\title{
PARA UMA PSICOLOGIA POPULAR NA AMÉRICA LATINA
}

\author{
Marilene Proença ${ }^{(*)}$ \\ Universidade de São Paulo, São Paulo, Brasil
}

Esta resenha traz ao público latino-americano uma obra ainda pouco conhecida e de grande importância para aqueles que constroem conhecimento e que produzem práticas alicerçadas em teorias críticas e libertárias no campo social. Trata-se da obra póstuma que compila grande parte das publicações do psicólogo social, Ignácio Martin-Baró, organizada por seu colega, catedrático em Psicologia Social, Amalio Blanco e intitulada Psicología de la Liberación, Madrid: Editorial Trotta, 1998, publicada após 10 anos de seu assassinato. O livro é composto por: Introdução, IV Seções assim intituladas: I - "El Fatalismo como Identidad Congnitiva", II - "El quehacer desideologizador de la Psicología", III - "La Liberación como vivencia de la Fe" e IV - "La Liberación como Exigencia de la Praxis", 10 capítulos e um Epílogo do linguista e ativista político Noam Chomsky que analisa o contexto político do assassinato de Martin-Baró.

Professor e Vice-Reitor da Universidade Centro-Americana "José Simeón Cañas" de El Salvador - UCA, Martin-Baró foi vítima daqueles que nele viram um empecilho para levar adiante planos de poder e de dominação tão presentes em solos dos países colonizados como El Salvador. Torturado e assassinado por milícias paramilitares, em sua própria casa, em 16 de novembro de 1989, com mais sete companheiros, Martin-Baró expressa as políticas internacionais e os projetos econômicos implantados nos países latino-americanos por meio da força do terrorismo de Estado. Como analisa Noam Chomsky, o assassinato de Martin-Baró revela aspectos da crueldade presente nas práticas utilizadas pelo governo estadunidense no que denomina o resgate da democracia na América Central, implantado principalmente durante a década de 1980.

Martin-Baró foi o mais importante pensador da psicologia latino-americana ao pautar a América Latina como o locus e focus de suas reflexões, práticas e proposições. Jesuíta e militante das classes populares, sua obra baseia-se nas concepções marxistas de sociedade e nos princípios da Teologia da Libertação, desenvolvida por Gustavo

(*) Professora Doutora, titular do Instituto de Psicologia da USP. 
Gutierrez, teólogo peruano que escreve a obra Teologia de la Liberación - perspectivas $(1971 / 2014)^{(1)}$. Enquanto importante instrumento da organização das classes populares, o ideário da teologia da libertação produziu importantes documentos internacionais que influenciaram sobremaneira algumas décadas de trabalho de organização popular no campo e nas cidades, entre 1970-1980. Martin-Baró anuncia em Hacia una Psicología de la liberación $(1986)^{(2)}$ :

[...] el problema más importante que confrontan las grandes mayorías latino-americanas es su situación de miseria opresiva, su condición de dependencia marginante que les impone una existencia inhumana y les arrebata la capacidad para definir su vida (p. 296).

Um dos grandes desafios para a Psicologia enquanto ciência e profissão, para Martin-Baró, está em realizar a crítica às teorias que buscam ajustar os indivíduos à sociedade sem questionar esta sociedade, o status quo, as formas de alienação e de opressão que conduzem à miséria e retiram de cada um dos indivíduos a possibilidade de definir suas próprias vidas e escolhas. Assim, caberá à Psicologia da libertação dos povos latino-americanos construir um novo campo epistemológico, uma práxis e um compromisso político com a libertação das situações de opressão a que estão submetidas as grandes maiorias latino-americanas.

A clareza de suas posições políticas e epistemológicas na direção de uma Psicologia da Libertação é apresentada por mais de 20 artigos e seis livros, mencionados nesta obra. Enraizado nas questões centro-americanas, o psicólogo social e pesquisador revela, por meio do materialismo histórico-dialético, sua análise psicossocial da realidade dos países e dos povos latino-americanos, destacando temas tais como: a guerra civil em El Salvador (1982)(3); Guerra e Saúde Mental (1984)(4); a ideologia dos setores médios salvadorenhos $(1986)^{(5)}$; a identidade nacional do salvadorenho (1987); a opinião pública salvadorenha (1989); bem como analisando temáticas mais abrangentes no campo social, tais como: "Os grupos com história: um modelo psicossocial" $(1988)^{(6)}$; Sistema, Grupo e Poder (1989); Realidade psicossocial do latino-americano: presente e futuro (1987); "Da consciência religiosa à consciência política (1985).

As bases de sua teoria são apresentadas na Introdução do livro Psicología de La Liberación (1998) por seu editor, Amalio Blanco, enquanto:

(1) Gutierrez, Gustavo. Teologia de la Liberación-perspectivas. Lima: Editorial: Centro de Estudios y Publicaciones (CEP) - Instituto Bartolomé de las Casas (IBC), 1971/2014

(2) Martin-Baró, Ignácio. Hacia una Psicología de la liberación. In: Boletín de Psicología, n. 22, p. 219-231, San Salvador: Universidad Centroamericana José Simeón Cañas Ed., 1986.

(3) Martin-Baró, Ignácio. Un psicólogo social ante la guerra civil en El Salvador. Revista de La Associación Lationamericana de Psicologia Social, n. 2, p. 91-111. Colômbia: Fundación Universitaria Konrad Lorenz, 1982.

(4) Martin-Baró, Ignácio. Guerra y Salud Mental. Estudios Centroamericanos, p. 429/430, 503-514. San Salvador: Universidad Centroamericana José Simeon Cañas Ed., 1984.

(5) Martin-Baró, Ignácio. La ideologia de los sectores medios salvadorenhos. Revista Mexicana de Psicología, n. 3, p. 59-65. México: Sociedade Mexicana de Psicologia, 1986.

(6) Martin-Baró, Ignácio. Los grupos con historia: un modelo psicosocial. Boletín de la Associación Venezuelana de Psicología Social, n. 11, p. 3-19. Venezuela: AVEPSO Ed., 1988. 
El de un hondo compromiso personal (nivel psicológico-biográfico) e institucional (nivel organizacional) para el estudio y la tranformación de una realidad marcada por la inhumanidad, la injusticia, por la conflictividad, por su fuerte carga alienante, por una división discriminante del trabajo, por la marginación y el desempleo masivos, y por la explotación y la represión (p. 16).

Para Martin-Baró, a constituição de uma Psicologia da Libertação é uma tarefa que parte da concretude da realidade social que passa a convocar conceitos psicológicos para explicá-la, de maneira a compreender tal realidade a partir de sua dimensão histórica e social. Desenvolve, portanto, um modelo teórico, no campo da Psicologia Social "desde a centro-américa", a partir do enfoque sócio-histórico em contraponto às posições pós-modernas, vigentes nas Ciências Humanas. A primazia do conceito de práxis em seu trabalho, toma como centro "[...] la lucha por restaurar el respecto y la dignidad de personas y de pueblos mancillados por siglos de opresión [...]" Psicología de La Liberación, 1988, (p. 19, Introducción); acrescenta-se a isso a historicização do comportamento tomando em conta o compromisso com as maiorias populares. Portanto, é fundamental compreender as raízes históricas dos parâmetros que se tornaram referência na Psicologia Social para explicar os comportamentos humanos, considerando as peculiaridades e os contextos em que ocorre esta produção teórica.

Sua crítica chama a atenção para o fato de que muitos dos temas clássicos da Psicologia Social, tais como: marginalidade, violência, poder, fenômenos grupais, processos de socialização, identidade, discriminação sexual, estereótipos, atitudes, cooperação e solidariedade são apresentados enquanto aspectos abstratos, de forma individualizada no sujeito e retirando desses temas sua dimensão histórica e social. Portanto, a teoria psicológica proposta por Martin-Baró tem como base três grandes eixos: compromisso (com as maiorias populares); "desideologização" (por meio da compreensão histórica dos fatos e teorias) e libertação (busca de formas de enfrentamento das barreiras que impedem a ação no campo social).

Uma de suas importantes contribuições constitui-se também no campo da formação de psicólogos, considerando a fundamental necessidade de construir um currículo que possa "desideologizar" a Psicologia, demonstrando as raízes históricas e psicológicas das teorias explicativas do desenvolvimento e do fazer humano, constituindo um processo de "conscientização". Parte, portanto, de questões básicas, a saber:

¿Como hablar de concientización socio-política si no tenemos consciencia ni de quiénes somos, ni de a quién servimos? Nuestra ubicación es necesaria, y sólo una vez realizada podemos preguntarmos como inventar un trabajo de conscientización en y con nuestro pueblo (Psicología de la Liberación, 1988, p. 137).

Para Martin-Baró, a conscientização é um processo que implica movimento e conflito; é um processo psicológico, pois a pessoa constitui uma nova consciência de sua própria realidade frente ao mundo; é um processo social, pois o sujeito da conscientização é, antes de tudo, uma comunidade, um povo. Para tanto, inspira-se em Paulo Freire que em Pedagogia do Oprimido (1970) ${ }^{(7)}$ considera que "Ninguém educa ninguém, ninguém educa a si mesmo, os homens se educam entre si, mediatizados pelo mundo", indicando,

(7) Freire, Paulo. Pedagogia del oprimido. Montevideo: Tierra Nueva, 1970. 
portanto, que o processo de formação é um processo comunitário, fundado no conceito marxista de "máximo de consciência possível". Portanto, todo processo de conscientização é, em essência, um processo político.

Ao final de sua vida, em 1989, realiza uma de suas últimas conferências pronunciada em Guadalajara (México), em que considera que a Psicologia ao assumir seu compromisso com as classes populares deverá se constituir em uma Psicologia popular. Destaca que a finalidade desta Psicologia popular deverá ser de recuperar a memória histórica dos povos latino-americanos, na perspectiva de Fals Borda $\left(1985\right.$, p. 139) ${ }^{(8)}$, na qual significa "[...] descobrir selectivamente mediante la memoria colectiva, elementos del pasado que fueron eficaces para defender los intereses de las clases explotadas y que vuelven outra vez a ser útiles para los objetivos de la lucha y de conscientización [...]"; reconhecer e potencializar as virtudes populares, formas simples de pensar, sentir e agir que permitiram que povos latino-americanos sobrevivessem a séculos de exploração e dominação; explorar novas formas de reflexão em um trabalho conscientizador, que supõe, dentre outros aspectos "[...] una articulación organizativa de las necesidades más profundas y de los intereses más autênticos de las propias clases populares, sin mediatizar essas necesidades y esos intereses a instancias partidistas [....]" (1985, p. 341). E enquanto Psicologia popular, é também uma Psicologia política.

Finalizamos esta resenha, convidando a todos e todas a conhecer este importante trabalho, referência para a América Latina e que destaca, dentre outros aspectos, os elementos essenciais para a construção de uma Psicologia da Libertação: a) a perspectiva de um novo horizonte que leve em conta o papel alienante das teorias psicológicas e que considere que as patologias e os transtornos comportamentais são produzidos na história e na sociedade; trabalhar por uma libertação na perspectiva de rupturas com as cadeias de opressão individual e social; b) a perspectiva de uma nova epistemologia construída a partir das camadas populares, que considere sua dimensão histórica e social, ou seja, uma revisão crítica do que se tem produzido a partir das maiorias populares; c) $a$ perspectiva de uma nova práxis, uma atividade transformadora da realidade que nos permita conhecer não somente o que ela é, mas o que ela não é e o como poderia ser. Nesse sentido, Martin-Baró destaca a importância de recuperação da memória histórica, "desideologização" da experiência cotidiana e a potencialização das virtudes de nossos povos.

A leitura ético-política de Martin-Baró, realizada a partir do campo de conhecimento da Psicologia, abre importantes questionamentos que, sem dúvida, se fazem presentes na área de Ciências Humanas e Sociais Aplicadas. Os questionamentos apontados pelo autor transversalizam a ciência e principalmente nos fazem repensar as ciências ditas humanas e sociais.

\section{REFERÊNCIA}

MARTIN-BARÓ, Ignácio. Psicologia de la Liberación. Madrid: Editorial Trotta, 1998, 374p. Edición, Introducción y Notas de Amalio Blanco e Epílogo de Noam Chomsky.

(8) Fals Borda, Orlando. Conocimiento y poder popular. Lecciones con campesinos de Nicarágua, México y Colombia. Bogotá: Siglo XXI, 1985. 